$\begin{array}{lll}\sum_{\text {Harvey O. Coxson }} & \equiv \\ & \text { Dept of Radiology, } & \text { Dept of Radiology, } \\ & \text { Vancouver General } & \text { Vancouver General } \\ & \text { Hospital, Vancouver, } & \text { Hospital, 855 West 12th Ave, } \\ \text { Canada } & \text { Room CP G22A, V5 Z1M9 BC } \\ & \text { Vancouver, Canada }\end{array}$

\title{
Lung parenchyma density and airwall thickness in airway diseases
}

\begin{abstract}
Aims
To describe the methodology and limitations of non-invasive imaging in quantifying lung structure.

To describe the opportunities for non-invasive imaging in understanding the structure of the lung, and how that relates to phenotyping subjects for clinical trials and longitudinal studies.
\end{abstract}

The development and proliferation of computed tomography (CT) scanners has greatly increased the information available to clinicians and researchers regarding the airways and lung parenchyma. Current CT scanners provide non-invasive images of these structures in vivo similar to those obtained at gross pathological examination. In the 1980 and 1990 these images consisted of thick crosssectional slices (i.e. $10 \mathrm{~mm}$ ) that appeared "blurry" because of the averaging of structures within the slice. In the last 10 years, the development of multi-detector row CT (MDCT) scanners has allowed the acquisition of sub-mm thickness images of the entire chest within a single breath-hold of 5-15 s. These new images can have the same resolution in the $X, Y$ and $Z$ dimensions (isometric voxels) allowing images to be reconstructed in any orientation without loss of spatial resolution (fig. 1). This has greatly facilitated the visualisation of airways and vessels that are oriented in a radial pattern around the pulmonary hila. Recent developments in CT have also improved the accuracy of lung density measurements, allowing accurate non-invasive evaluation of the air soft-tissue matrix within the peripheral lung. As a result changes in lung density can be accurately tracked using computer programs. These lung density measurements allow the calculation of the tissue and gas volumes in peripheral lung tissue and correlate with emphysematous lung destruction and hyperinflation of the lung [1-8].

The clinical utility of current CT scanners for non-invasive evaluation of chest disease cannot be overstated. Diseases that present with indistinguishable history and physical findings can be reliably separated on the basis of characteristic alterations in the airway, vascular and lung parenchymal findings on chest CT images. This improves disease
Statement of interest H.O. Coxson received $\$ 4,800$ in the years 2008-2012 for serving on the steering committee for the ECLIPSE project for GSK. In addition, the author was the co-investigator on two multicentre studies sponsored by GSK and has received travel expenses to attend meetings related to the project. He has three contract service agreements with GSK to quantify computed tomography scans in subjects with chronic obstructive pulmonary disease and a service agreement with Spiration Inc. to measure changes in lung volume in subjects with severe emphysema. He has received a fee for speaking at a conference and related travel expenses from AstraZeneca (Australia). He was the recipient of a GSK Clinical Scientist Award in 2010.

HERMES syllabus link: module D.3.1 


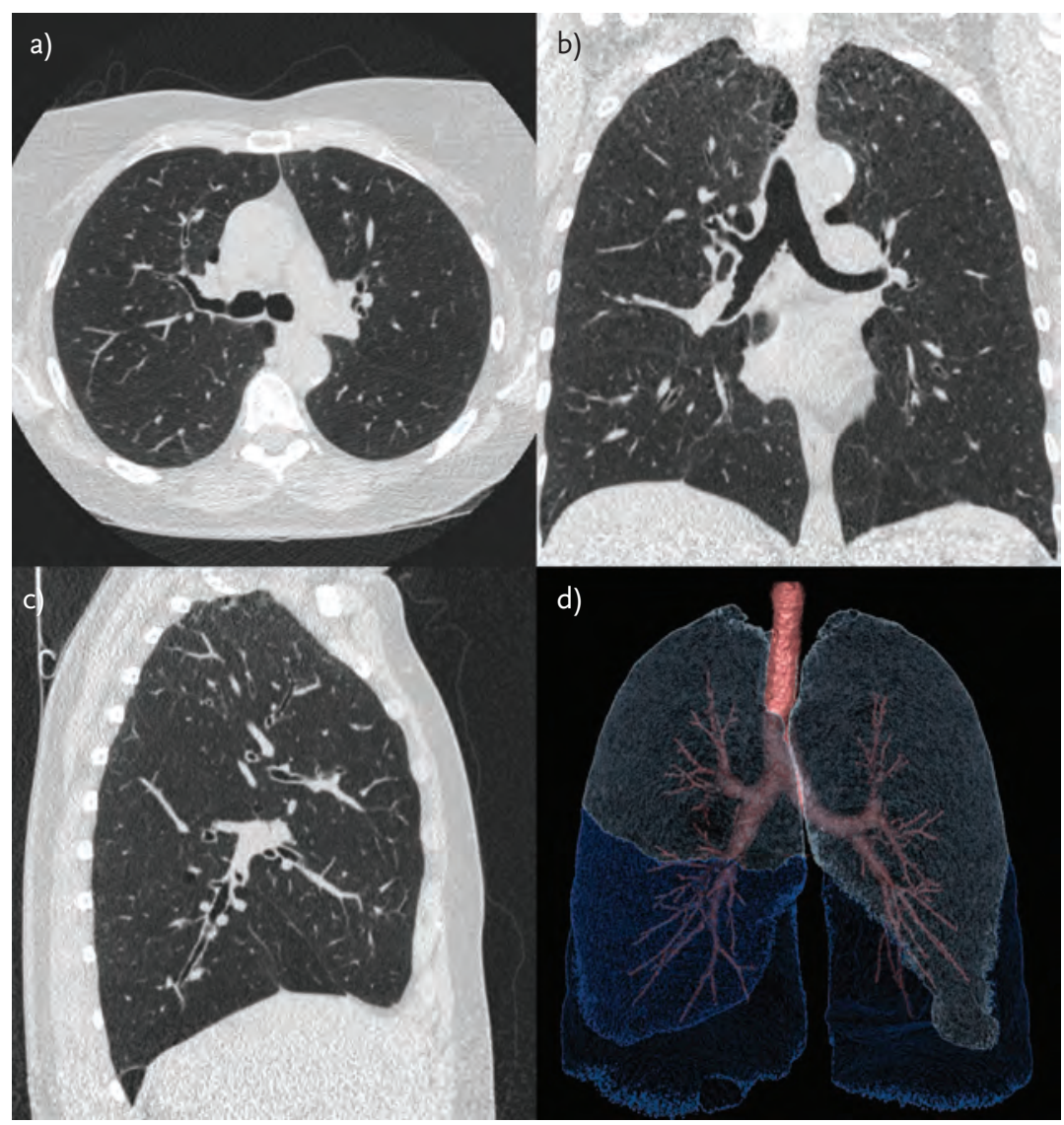

\section{Figure 1}

This figure shows a CT scan acquired using a multi-detector row CT scanner. a) The conventional transverse image and the b) coronal and c) sagittal reformats of the CT data are shown. d) A 3-dimensional reconstruction of the airway tree and the lung. (Images were captured using the Pulmonary Workstation 2.0 image analysis software (VIDA Diagnostics, Coralville, IA, USA).

classification, improving the match of disease to treatment. Follow up CT imaging may improve the assessment of treatment, tailoring the selection of drugs and optimising the timing of surgical interventions. Finally, the CT scanner environment is user friendly to patients with respiratory diseases, obtaining diagnostic images using less than a 5-s breath-hold period and presenting a benign environment to monitored and intubated patients.

\section{Quantitative CT analysis of lung parenchyma}

It is important to remember that the CT scan images consist of more than the two-dimensional picture elements (pixels) that are displayed on a computer screen (or printed on film). These pixels also contain a third dimension, the thickness of the CT slice, which makes more appropriately titled volume elements (voxels). The fact that these voxels have a set volume allows an investigator to calculate the volume of the lung by multiplying the number of CT lung voxels by the dimension of the voxel. There is general agreement that most lung segmentation algorithms can reliably and accurately measure lung volume [9]. The recent improvement in these algorithms to accurately measure lobar volume is a direct result of the new MDCT scanners that obtain contiguous thin slice images of the entire lung making it possible to visualise the fissures (fig. 1) [10-16]. Cross sectional studies of lung volume have shown that in COPD there is an increase in lung volume from unaffected levels $[2,17,18]$. Intervention studies using surgical procedures (lung volume reduction surgery) or intrabronchial valves have shown that there is a reduction in either total lung volume (LVRS) [19-23] or the treated lobes (bronchial valves) [24].

The CT scan voxels are also measurements of the apparent $X$-ray attenuation value of the tissue. This attenuation value, measured in Hounsfield units $(\mathrm{HU})$, gives an indication of the density of the lung and, using this density value, investigators have been able to calculate lung mass, tissue volume and airspace volume $[1,18,21]$. Another derived variable that can be calculated from density is the regional lung inflation, which is an estimate of the volume of gas per gram of lung tissue present in the lung $[1,25]$. The extent and severity of emphysema is usually estimated using one of two common methods: the threshold cut-off analysis or the percentile point analysis $[1,2,5,6,22,26-41]$. The threshold analysis, in which the per cent of voxels with attenuation values less than a predetermined threshold point is considered to be emphysema. The most common threshold point in use today is -950 $\mathrm{HU}$ [28] even though more recent data suggests that for multidetector CT scanners -960 HU would be a better cut-off value [42]. It has also been shown that an estimate of the emphysematous lesion size can be performed by plotting the cumulative number of low attenuating voxels (a cluster of low attenuating voxels) that are connected to a neighbouring low attenuation voxel against the cumulative size of this cluster on a log-log plot (fig. 2) [39, 43, 44]. The slope of this relationship is the power-law exponent (D) and subjects with small clusters (emphysematous holes) have a very steep slope (large D) while subjects with large clusters have a very flat slope. This metric has been shown to 

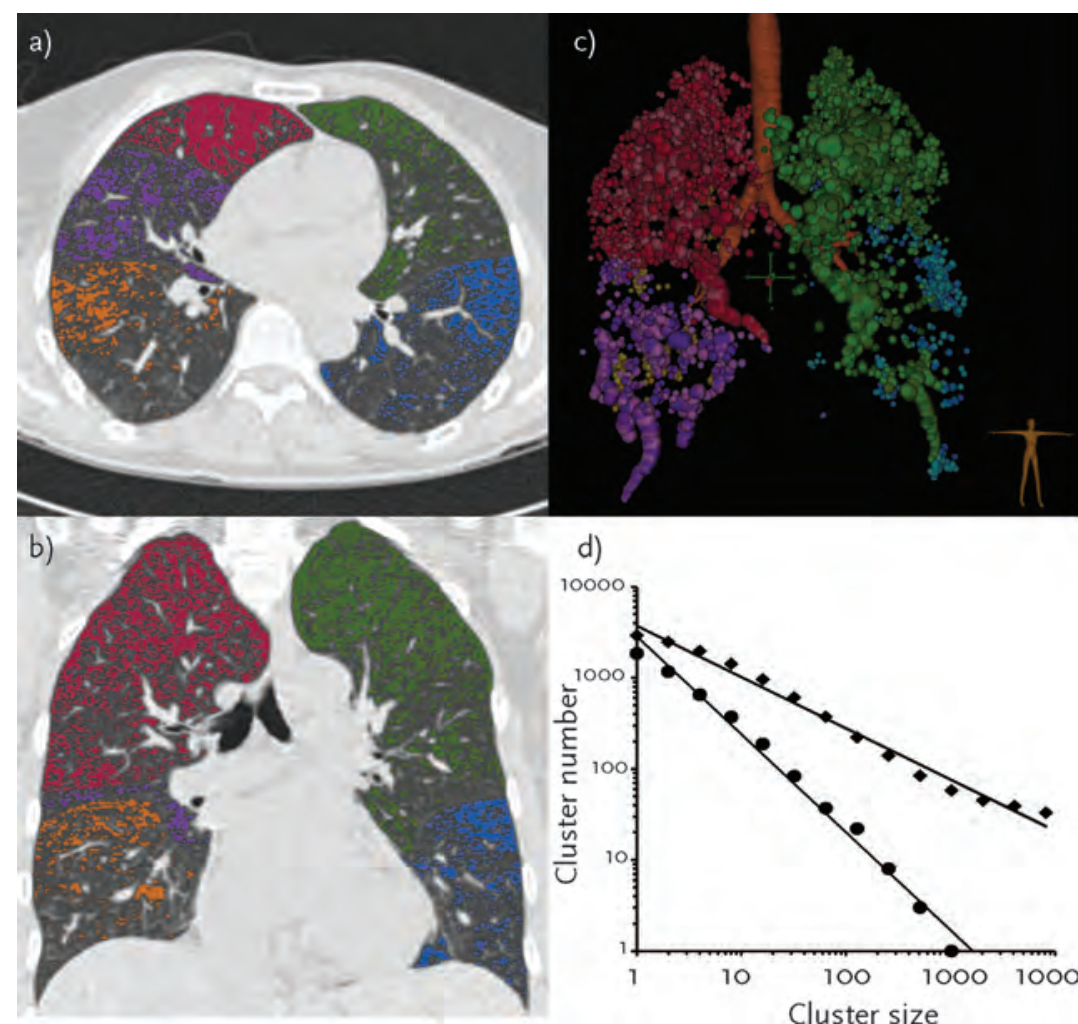

d)

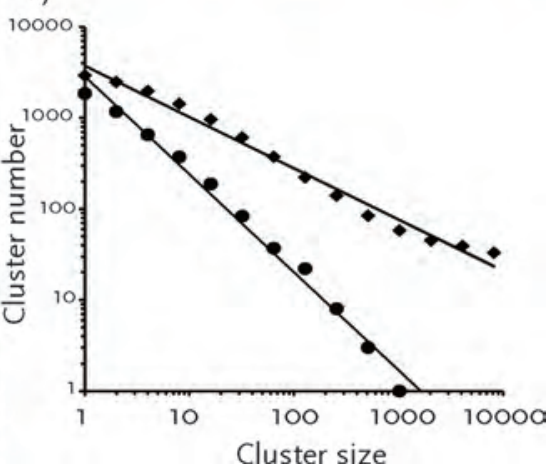

Figure 2

Spatial distribution of low attenuation regions within the lung. The CT voxels with attenuation values less than -950 HU presented in the a) transverse and b) coronal view. Each colour represents voxels from a different lobe. c) Low attenuation voxels are connected to form low attenuation clusters. The number of connected low attenuation voxels is suggestive of larger emphysematous spaces within the lung and are illustrated using low attenuation cluster "balls". d) A plot of the number of clusters versus the size of the clusters; the slope of this relationship is a power-law relationship (D) and a normal subject with a steep slope (large $D)$ is shown using the circles (๑) and a subject with severe emphysema and a less steep slope (small D) is shown using diamonds ( $\bullet$ ). Images were captured using the Pulmonary Workstation 2.0 (VIDA Diagnostics, Coralville, IA, USA).

correlate with survival [43] and exercise ability following lung volume reduction surgery [39], but has not been shown to correlate very well with pathological measurements of emphysema [45]. The second approach is the percentile method, in which a specific point on the frequency distribution curve of the X-ray attenuation values is defined and compared between subjects or groups of subjects. The percentile value most commonly used today is the lowest 15th percentile cut-off value [29-37]. Numerous studies have shown that these studies all give reasonable estimates of the extent of disease in cross sectional studies $[1,2,22,30-32,34,36,38-41]$. It is important to note here that the parameters used to obtain the CT image including the inspiration level of the subject, the slice thickness, the reconstruction algorithm, the exposure of the $\mathrm{CT}$ scanner $(\mathrm{kVp}, \mathrm{mA})$ and even the type of CT scanner (number of detectors, manufacturer, etc.) can all effect these measurements of lung density
$[31,33,46-49]$. A summary of these measurements is shown in table 1.

In a recent workshop hosted by the Alpha-1 Foundation and the COPD Foundation it was recommended that for cross-sectional studies of COPD, either the threshold cut-off analysis or the percentile point analysis can be used as either provides useful information about the extent of emphysema [9]. In longitudinal studies it was recommended that the volume-corrected percentile approach be used because this approach is less sensitive to minor changes in the technical aspects of the CT scan (image noise caused by CT scanner, reconstruction algorithm, etc.) and more sensitive to changes in lung structure $[9,46,47,50]$. Volume analysis of the lung has proven to be very robust across many different CT platforms and image analysis algorithms, so the volume measurements are strongly recommended not only for correction of the density data but for studies that require information on lung or lobar volume changes. 
Table 1. Lung parenchyma and emphysema parameters measured and derived using quantitative computed tomography

\begin{tabular}{|c|c|c|c|c|}
\hline \multicolumn{2}{|l|}{ Measured parameters } & \multirow{3}{*}{$\begin{array}{l}\text { Confounding factors } \\
\text { - Spatial resolution } \\
\text { - Inspiration level }\end{array}$} & \multicolumn{2}{|c|}{ Derived parameters } \\
\hline Volume & Sum of voxels & & Mass & Volume X CT density \\
\hline Lobar & $\begin{array}{l}\text { Sum of voxels on } \\
\text { specific lobes }\end{array}$ & & Air volume & $\begin{array}{l}\text { Total volume - tissue } \\
\text { volume }\end{array}$ \\
\hline \multirow[t]{2}{*}{$\begin{array}{l}\text { X-ray attenuation } \\
\text { (measured in } \mathrm{HU} \text { ) }\end{array}$} & & $\begin{array}{l}\text { - Image noise } \\
\text { - Inspiration level }\end{array}$ & $\mathrm{CT}$ density $\left(\mathrm{g} \cdot \mathrm{mL}^{-1}\right)$ & $(H U+1000) / 1000$ \\
\hline & & & Specific lung inflation & $\begin{array}{l}\text { (1/CT density) - } \\
\text { (1/tissue density) }\end{array}$ \\
\hline Percentile & $\begin{array}{l}\mathrm{HU} \text { at pre-defined } \\
\text { percentile value of } \\
\text { frequency } \\
\text { distribution of X-ray } \\
\text { attenutation values } \\
\text { (i.e. lowest 15th } \\
\text { percentile) }\end{array}$ & $\begin{array}{l}\text { - Image noise } \\
\text { - Inspiration level }\end{array}$ & & \\
\hline
\end{tabular}

Table 2. Airway parameters measured and derived using quantitative computed tomography

\begin{tabular}{|c|c|c|c|c|}
\hline \multicolumn{2}{|l|}{ Measured parameters } & \multirow{2}{*}{$\begin{array}{l}\text { Confounding factors } \\
\begin{array}{l}\text { - Spatial resolution } \\
\text { - Image noise } \\
\text { - Inspiration level }\end{array}\end{array}$} & \multirow{2}{*}{\multicolumn{2}{|c|}{$\begin{array}{lc} & \text { Derived parameters } \\
\text { area } \% & \text { Aaw/Ao }\end{array}$}} \\
\hline Lumen area & $\mathrm{Ai}$ & & & \\
\hline Wall thickness & $\mathrm{T}$ & & & \\
\hline Internal lumen perimeter & $\mathrm{Pi}$ & & & \\
\hline \multicolumn{2}{|l|}{ Branch angle } & & & \\
\hline
\end{tabular}




\section{Airway analysis}

Recently there has been a great deal of interest in the measurement of airway wall and lumen dimensions (table 2) $[11,12,51-70]$. Originally investigators were limited by the fact that CT scans were cross-sectional images of the lung and therefore measurements of airway dimensions were only performed on airways that were cut in cross section (fig. 3). Studies using these techniques have shown that there is a correlation between airway wall dimensions and airflow limitation (forced expiratory volume $\left.\left(F E V_{1}\right)\right)[62,67,70,71]$. However, what everyone recognises is that the airflow limitation in COPD is caused by airways that are below the resolution of the CT scanner. NAKANO et al. [64] compared CT measurements and of "medium-to-large" airways to the dimensions of the small airways measured using histology and found that while there was an offset between the two measurements, they were correlated, suggesting that $\mathrm{CT}$ measures something in the large airways that reflects the inflammatory changes in the small airways.

The most attractive method for measuring airways today is exploiting the new MDCT scanners to produce three-dimensional reconstructions of the airway tree. This approach has great advantages over the cross sectional approach, because it is now possible to identify and measure a specific airway at a specific location. For example, it is possible to identify the left apical segmental bronchus ( $\mathrm{LB} 1$ ) or the right lateral basal segmental bronchus (RBg) and follow it from its origin as far as the reconstruction goes and measure the length of each segment and the angle at branch points (fig. 4) [12]. Using this approach, HASEGAWA et al. [70] measured the airway at progressively small generations (i.e. 5th or 6th generation) and found that the correlations with spirometry improved in the more distal segments. What these studies have shown is that airway measurements using $\mathrm{CT}$ are an important tool in the understanding of COPD but, at the current time, there are almost as many different airway measurement algorithms in use as there are centres that are using them, each with their own strengths and weaknesses. Some of the characteristics of airway techniques are shown in table 2. A more thorough review of these methods can be found in the Alpha-1 Foundation Workshop summary [9, 72]. Finally it should be noted that many of the airways of interest are below the resolution of

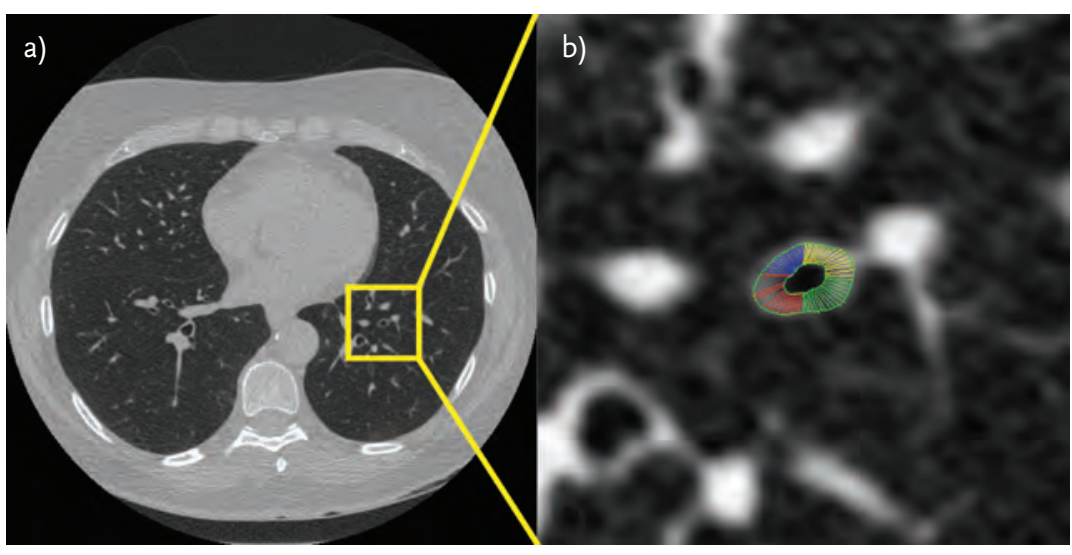

Figure 3

a) Transverse CT image with a region of airways cut in cross section shown in the yellow box. b) Expanded version of the box with a measured airway. Images created using the Emphylxj image analysis software (University of British Columbia, Vancouver, Canada).

the CT scanner. For this reason investigators have recently turned their attention to expiratory CT scans as a method of measuring the extent of "gas trapping" which is thought to be due to small airway remodelling. To use this technique, investigators obtain CT scans at suspended full expiration. Then, using a threshold value of $-856 \mathrm{HU}$, which has been shown to correlate to maximal lung inflation [1], the percentage of the lung beyond this point is calculated. Since this point can be considered

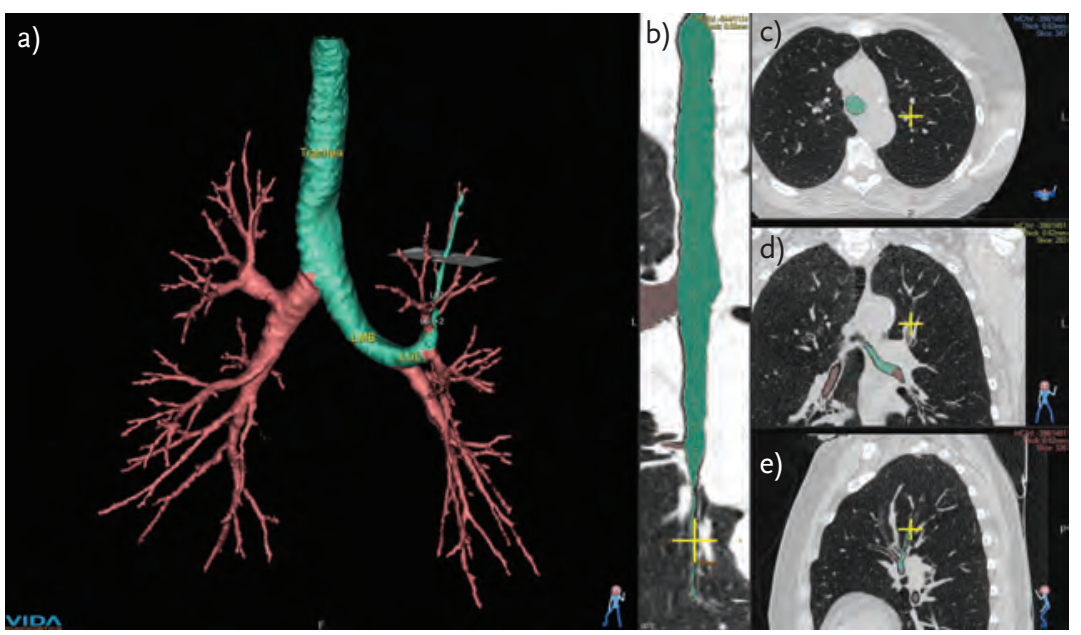

\section{Figure 4}

Analysis of the airway tree using a multi-detector row CT scan and commercially available CT analysis software. Using this approach, the airway tree is reconstructed in three dimensions and the airway can be analysed at any location within the tree in a plane that is cross-sectional to the centre line of the airway. a) 3-dimensional reconstruction of the airway tree with the airway path of interest highlighted in green. b) Longitudinal section of a reformatted airway path from a and the yellow cross is the site of the airway measurement and is shown as a small "CT view". The airway at the site of measurement is shown by the yellow cross in the transverse plane (c), the coronal plane and the sagittal plane (d). (Images created using the Apollo image analysis software (VIDA Diagnostics, Coralville, IA, USA)). 


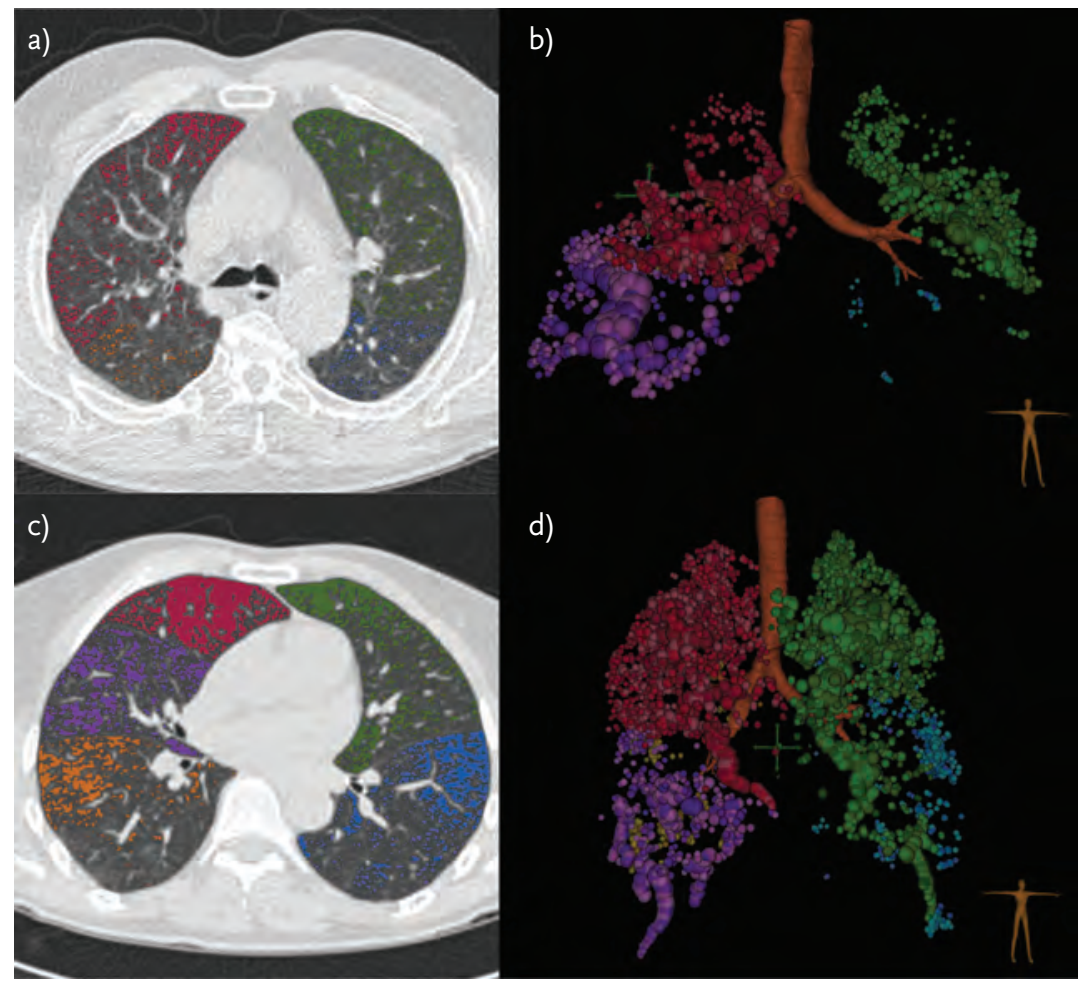

Figure 5

Analysis of the "gas trapping" using expiratory CT scans. The subject in a) and b) exhibits minimal gas trapping as indicated by the lower percentage of voxels below $-856 \mathrm{HU}$ (highlighted in colour) while the subject in c) and d) has many more highlighted voxels indicating more severe gas trapping. a) and c) Transverse CT images showing the voxels less than $-856 \mathrm{HU}$; b) and d) show these same voxels using the cluster analysis. Images were captured using the Pulmonary Workstation 2.0 image analysis software (VIDA Diagnostics, Coralville, IA, USA).

maximally inflated, lung with attenuation values less than this point are considered to be hyper inflated and represent gas trapping (fig. 5). While it should be pointed out that this is only a surrogate measurement of airway disease the results have been promising so far. BUSACKER et al. [73] have shown in severe asthmatic subjects that those subjects with the most "gas trapping" measured using CT are also the subjects with the most severe asthma symptoms and require the most hospitalisations.

\section{Quantitative studies of COPD using CT}

It is well accepted that there are likely numerous phenotypes of COPD. One possible method for understanding the phenotypes of COPD is to understand the anatomy of the lung and this is why CT is so popular in current research protocols. The most obvious place to start when describing the lung structure is to group subjects according to emphysema distribution and airway wall thickness. The distribution of emphysema has shown some promise in LVRS where subjects with emphysema predominately located in the upper regions of the lung had improved cardiopulmonary exercise ability shortly after surgery and a long-term survival advantage [39, 43, 74]. In one of the first studies to combine measurements of both airway wall dimensions and the extent of emphysema it was shown that both measurements were independently associated with lung function [62]. Furthermore, different aspects of pulmonary function related differently to airways (i.e. forced vital capacity (FVC)) or emphysema (FEV1/FVC, diffusing capacity of the lung for $\mathrm{CO}(D \mathrm{~L}, \mathrm{CO}))$ and that some subjects could be divided into an airway predominate or emphysema predominate phenotype [62, 71]. Other studies have shown that patients with COPD and the clinical diagnosis of chronic bronchitis had thicker airway walls than those without chronic bronchitis and COPD [75]. This study was followed by another that showed that the distribution of emphysema, centrally (core) versus peripherally (rind) and bronchial wall thickness have independent influences on airflow limitation and diffusion of gas [76]. Recently, work by PATEL et al. [67] showed that the airway and emphysema phenotypes have a familial association such that COPD patients with increased wall thickness had siblings with increased wall thickness and patients with emphysema had siblings with increased emphysema [6]]. It is important to note that none of the published studies so far showed a strong association correlation with lung function but that only further underlines the fact that it is a very complicated task to phenotype individuals with COPD. However, the published data do suggest that measurement of emphysema and airway wall dimensions are important in subjects with COPD because they may give insight into different pathogenic processes responsible for the disease. Finally, there have been several studies that have combined qualitative and quantitative $\mathrm{CT}$ measurements of lung structure. One recent study combined qualitative assessment of interstitial lung disease features with quantitative emphysema measurements. This study found that in a COPD cohort changes in lung parenchyma thought to represent interstitial lung disease abnormalities was prevalent (about one out of every 12 HRCT scans) and was associated with reduced total lung capacity and a lesser amount of emphysema [77]. In another study qualitative assessments of emphysema were 
combined with quantitative emphysema, and while there was a correlation between the two estimates the best predictor of an increase in qualitative assessment was the quantitative assessment of how the low attenuation areas were clustered together [78].

\section{Limitations to quantitative CT}

While CT is a powerful tool for the analysis of lung structure, it does have some limitations and caveats for general use including disagreements on the best method to analyse the lung parenchyma, no definitive study using airway wall algorithms, exposure of subjects to ionizing radiation, and, most importantly, the lack of longitudinal studies involving sufficient numbers of subjects and properly calibrated CT scanners and standardized imaging techniques. It is for these reasons that the Alpha-1 Foundation and the COPD Foundation recently held a workshop on the use of quantitative CT in longitudinal studies where the strengths and weakness of CT were discussed and debated and a full listing of outcome from that meeting can be found in the Proceedings of the American Thoracic Society [9].

\section{$\mathrm{X}$-ray exposure}

A discussion of CT is not complete without a comment on its major limitation, a relatively high level of radiation exposure when compared to plain radiography studies (i.e. PA and lateral chest radiograph). While the actual effects of the level of radiation exposure delivered in a standard chest CT examination remains controversial there is increasing evidence that this level of exposure is potentially associated with a small increase in the rate of cancer in long term (>20 years) follow up. It is generally accepted that radiation effects are much more significant in younger compared to older individuals, therefore CT use should be strongly constrained in children, used cautiously in young adults and used prudently in older adults. As well, in all situations it is recommended that the radiation dose be as low as possible for the diagnostic question posed for all CT examinations. This conforms to the time honoured ALARA principle, "as low as reasonably achievable" [79, 80]. Because image noise within the CT scan is also dependant of the dose of the scan questions involving the lung parenchyma may be answered using a very low radiation dose while airway analysis may require a higher dose $[49,80]$.

\section{Conclusions}

In conclusion, it is generally accepted that COPD is a complex disease with complex interactions between genetics and environmental exposures. However, non-invasive imaging such as CT imaging has provided a great deal of hope that with careful anatomic studies correlated with physiologic symptoms this devastating disease can be understood at a level that allows appropriate intervention.

\section{Acknowledgements}

Special thanks to Natasha Krowchuk for help preparing the figures.

\section{References}

1. Coxson HO, Mayo JR, Behzad H, et al. Measurement of lung expansion with computed tomography and comparison with quantitative histology. J Appl Physiol 1995; 79: 1525-1530.

2. Coxson HO, Rogers RM, Whittall KP, et al. A quantification of the lung surface area in emphysema using computed tomography. Am J Respir Crit Care Med 1999; 159: 851-856.

3. Gevenois PA, de Maertelaer V, De Vuyst P, et al. Comparison of computed density and macroscopic morphometry in pulmonary emphysema. Am J Respir Crit Care Med 1995; 152: 653-657.

4. Gevenois PA, De Vuyst P, Sy M, et al. Pulmonary emphysema: Quantitative CT during expiration. Radiology 1996; 199: 825-829.
5. Hayhurst MD, Flenley DC, McLean A, et al. Diagnosis of pulmonary emphysema by computerized tomography. Lancet 1984; 2: 320-322.

6. Müller NL, Staples CA, Miller RR, et al. "Density mask". An objective method to quantitate emphysema using computed tomography. Chest 1988; 94: 782-787.

7. Nakano Y, Sakai H, Muro S, et al. Comparison of low attenuation areas on computed tomographic scans between inner and outer segments of the lung in patients with chronic obstructive pulmonary disease: Incidence and contribution to lung function. Thorax 1999; 54: 384-389

8. Stolk J, Versteegh MI, Montenij LJ, et al. Densitometry for assessment of effect of lung volume reduction surgery for emphysema. Eur Respir J 2007; 29: 1138-1143.

\section{Educational questions}

1. Which answer best describes the methodology to estimate the emphysema in subjects with COPD?

a. The slope of the relationship between the size of clusters of low attenuating regions within the lung and the number of these regions is thought to represent emphysematous holes

b. The percentage of $\mathrm{CT}$ voxels with $\mathrm{X}$-ray attenuation values less than a defined threshold point are considered to be emphysema

c. The X-ray attenuation value at which $15 \%$ of the are lower in attenuation is described as emphysema

d. All of the above

2. What are some of the major limitations of CT imaging in quantifying of the lung structure: 1) Radiation dose; 2) pathologic validation; 3 ) appropriate algorithms and method of measurement; 4) lack sufficient longitudinal studies; 5) availability of CT scanners; 6) calibration of the CT scanner?
a. All of the above
b. $1,2,3$
c. $4,5,6$
d. $1,3,4,6$
e. None of the above 
3. There are numerous methods to quantify airway wall structure. Which of these is the most popular method?

a. Score guided erosion

b. Point spread function

c. Full-width-at half maximum

d. Model-based algorithms

4. Which of these is an appropriate method to measure gas trapping using $\mathrm{CT}$ ?

a. Threshold analysis at expiration

b. Percentile analysis at expiration

c. Wall area as a percentage of total airway wall area at expiration

d. Lung volume at expiration

5. Non-invasive imaging to understanding the structure of the lung is important because it...

a. provides insight into pathogenesis

b. can identify response to interventions

c. allows the relationship of function to structure d. dose all of the above
9. Coxson HO. Quantitative chest tomography in COPD research: Chairman's summary. Proc Am Thorac Soc 2008; 5: 874-877.

10. Zhang L, Hoffman EA, Reinhardt JM. Lung lobar segmentation by graph search with 3D shape constraints. Proc SPIE 2001; 4321: 204-215.

11. Montaudon M, Berger P, de Dietrich G, et al. Assessment of airways with three-dimensional quantitative thin-section $\mathrm{CT}$ : in vitro and in vivo validation. Radiology 2007; 242: 563-572.

12. Tschirren J, Hoffman EA, McLennan G, et al. Intrathoracic airway trees: segmentation and airway morphology analysis from low-dose CT scans. IEEE Trans Med Imaging 2005; 24: 1529-1539.

13. Hu S, Hoffman EA, Reinhardt JM. Automatic lung segmentation for accurate quantitation of volumetric $x$-ray CT images. IEEE Trans Med Imaging 2001; 20: 490-498.

14. Kuhnighk J, Hahn HK, Hindennach M, et al. Lung lobe segmentation by anatomy-guided 3D watershed transform. Proc SPIE 2003; 5032: 1484-1490.

15. Ukil S, Hoffman EA, Reinhardt JM. Automatic lung lobe segmentation in $\mathrm{x}$-ray $\mathrm{CT}$ images by $3 \mathrm{~d}$ watershed transform using anatomic information from the segmented airway tree. Proc SPIE 2005; 5747: 556-567.

16. Zhang L, Hoffman EA, Reinhardt JM. Altas-driven lung lobe segmentation in volumetric $x$-ray CT images. Proc SPIE 2003; 25: 1-16.

17. Dransfield MT, Washko GR, Foreman MG, et al. Gender differences in the severity of CT emphysema in COPD. Chest 2007; 132: 464-470.

18. Millar AB, Fromson B, Strickland BA, et al. Computed tomography based estimates of regional gas and tissue volume of the lung in supine subjects with chronic airflow limitation or fibrosing alveolitis. Thorax 1986; 41: 932-939.

19. Bae KT, Slone RM, Gierada DS, et al. Patients with emphysema: quantitative $\mathrm{CT}$ analysis before and after lung volume reduction surgery. Work in progress. Radiology 1997; 203: 705-714.

20. Gierada DS, Slone RM, Bae KT, et al. Pulmonary emphysema: comparison of preoperative quantitative $C T$ and physiologic index values with clinical outcome after lung-volume reduction surgery. Radiology 1997; 205: 235-242.

21. Rogers RM, Coxson HO, Sciurba FC, et al. Preoperative severity of emphysema predictive of improvement after lung volume reduction surgery: use of CT morphometry. Chest 2000; 118: 1240-1247.

22. Stolk J, Versteegh MIM, Montenij LJ, et al. Densitometry for assessment of effect of lung volume reduction surgery for emphysema. Eur Respir J 2007; 29: 1075-1077.

23. Becker MD, Berkmen YM, Austin JH, et al. Lung volumes before and after lung volume reduction surgery: Quantitative CT analysis. Am J Respir Crit Care Med 1998; 157: 1593-1599.

24. Coxson HO, Nasute Fauerbach PV, Storness-Bliss C, et al. Computed tomography assessment of lung volume changes after bronchial valve treatment. Eur Respir J 2008; 32: 1443-1450.

25. Hogg JC, Nepszy S. Regional lung volume and pleural pressure gradient estimated from lung density in dogs. J Appl Physiol 1969; 27: 198-203.

26. Miller RR, Müller NL, Vedal S, et al. Limitations of computed tomography in the assessment of emphysema. Am Rev Respir Dis 1989; 139: 980-983.

27. Gould GA, MacNee W, McLean A, et al. CT measurements of lung density in life can quantitate distal airspace enlargement-an essential defining feature of human emphysema. Am Rev Respir Dis 1988; 137: 380-392.
28. Gevenois PA, De Vuyst P, de Maertelaer V, et al. Comparison of computed density and microscopic morphometry in pulmonary emphysema. Am J Respir Crit Care Med 1996; 154: 187-192.

29. Newell JD Jr, Hogg JC, Snider GL. Report of a workshop: Quantitative computed tomography scanning in longitudinal studies of emphysema. Eur Respir J 2004; 23: 769-775.

30. Shaker SB, Dirksen A, Laursen LC, et al. Short-term reproducibility of computed tomography-based lung density measurements in alpha- 1 antitrypsin deficiency and smokers with emphysema. Acta Radiol 2004; 45: 424-430.

31. Stolk J, Dirksen A, van der Lugt AA, et al. Repeatability of lung density measurements with lowdose computed tomography in subjects with alpha-1antitrypsin deficiency-associated emphysema. Invest Radiol 2001; 36: 648-651.

32. Stolk J, Ng WH, Bakker ME, et al. Correlation between annual change in health status and computer tomography derived lung density in subjects with alphar-antitrypsin deficiency. Thorax 2003; 58: 1027-1030.

33. Parr DG, Stoel BC, Stolk J, et al. Influence of calibration on densitometric studies of emphysema progression using computed tomography. Am J Respir Crit Care Med 2004; 170: 883-890.

34. Parr DG, Stoel BC, Stolk J, et al. Pattern of emphysema distribution in $\alpha 1$-antitrypsin deficiency influences lung function impairment. Am J Respir Crit Care Med 2004; 170: 1172-1178.

35. Dirksen A, Dijkman JH, Madsen IF, et al. A randomized clinical trial of $\alpha-1$ antitrypsin augmentation therapy. Am J Respir Crit Care Med 1999; 160: 1468-1472.

36. Dirksen A, Friis M, Olesen KP, et al. Progress of emphysema in severe $\alpha$-antitrypsin deficiency as assessed by annual CT. Acta Radiologica 1997; 38: 826-832.

37. Stoel BC, Bakker ME, Stolk J, et al. Comparison of the sensitivities of 5 different computed tomography scanners for the assessment of the progression of pulmonary emphysema: a phantom study. Invest Radiol 2004; 39: 1-7.

38. Coxson HO, Chan IH, Mayo JR, et al. Early emphysema in patients with anorexia nervosa. Am J Respir Crit Care Med 2004; 170: 748-752.

39. Coxson HO, Whittall KP, Nakano Y, et al. Selection of patients for lung volume reduction surgery using a power law analysis of the computed tomographic scan. Thorax 2003; 58: 510-514.

40. DeMeo DL, Hersh CP, Hoffman EA, et al. Genetic determinants of emphysema distribution in the national emphysema treatment trial. Am J Respir Crit Care Med 2007; 176: 42-48.

41. Zagers H, Vrooman HA, Aarts N), et al. Assessment of the progression of emphysema by quantitative analysis of spirometrically gated computed tomography images. Invest Radiol 1996; 31: 761-767.

42. Madani A, Zanen I, de Maertelaer V, et al. Pulmonary emphysema: Objective quantification at multi-detector row CT - comparison with macroscopic and microscopic morphometry. Radiology 2006; 238: 1036-1043

43. Martinez FJ, Foster G, Curtis JL, et al. Predictors of mortality in patients with emphysema and severe airflow obstruction. Am J Respir Crit Care Med 2006; 173: 1326-1334.

44. Mishima M, Hirai $\mathrm{T}$, Itoh $\mathrm{H}$, et al. Complexity of terminal airspace geometry assessed by lung computed tomography in normal subjects and patients with chronic obstructive pulmonary disease. Proc Natl Acad Sci USA 1999; 96: 8829-8834. 
45. Madani A, Van Muylem A, de Maertelaer V, et al. Pulmonary emphysema: size distribution of emphysematous spaces on multidetector CT imagescomparison with macroscopic and microscopic morphometry. Radiology 2008; 248: 1036-1041.

46. Stoel BC, Bode F, Rames A, et al. Quality control in longitudinal studies with computed tomographic densitometry of the lungs. Proc Am Thorac Soc 2008; 5: 929-933.

47. Stoel BC, Putter H, Bakker ME, et al. Volume correction in computed tomography densitometry for follow-up studies on pulmonary emphysema. Proc Am Thorac Soc 2008; 5: 919-924.

48. Stoel BC, Vrooman HA, Stolk J, et al. Sources of error in lung densitometry with CT. Invest Radiol 1999; 34: 303-309.

49. Yuan R, Mayo JR, Hogg JC, et al. The effects of radiation dose and CT manufacturer on measurements of lung densitometry. Chest 2007; 132: 617-623.

50. Dirksen A. Monitoring the progress of emphysema by repeat computed tomography scans with focus on noise reduction. Proc Am Thorac Soc 2008; 5 : 925-928.

51. Brown MS, Goldin JG, McNitt-Gray MF, et al. Knowledge-based segmentation of thoracic computed tomography images for assessment of split lung function. Med Phys 2000; 27: 592-598.

52. Chaturvedi A, Lee Z. Three-dimensional segmentation and skeletonization to build airway tree data structure for small animals. Phys Med Biol 2005; 50: 1405-1419.

53. Ferretti GR, Vining DJ, Knoplioch J, et al. Tracheobronchial tree: three-dimensional spiral CT with bronchoscopic perspective. J Comput Assist Tomogr 1996; 20: 777-781.

54. King GG, Muller NL, Pare PD. Evaluation of airways in obstructive pulmonary disease using high-resolution computed tomography. Am J Respir Crit Care Med 1999; 159: 992-1004.

55. King GG, Muller NL, Whittall KP, et al. An analysis algorithm for measuring airway lumen and wall areas from high-resolution computed tomographic data. Am J Respir Crit Care Med 2000; 161: 574-580.

56. Matsuoka S, Kurihara Y, Nakajima Y, et al. Serial change in airway lumen and wall thickness at thinsection CT in asymptomatic subjects. Radiology 2005; 234: 595-603.

57. Matsuoka S, Kurihara Y, Yagihashi K, et al. Airway dimensions at inspiratory and expiratory multisection $\mathrm{CT}$ in chronic obstructive pulmonary disease: Correlation with airflow limitation. Radiology 2008; 248: 1042-1049.

58. McNamara AE, Muller NL, Okazawa M, et al. Airway narrowing in excised canine lung measured by highresolution computed tomography. J Appl Physiol 1992; 73: 307-316.

59. McNitt-Gray MF, Goldin JG, Johnson TD, et al. Development and testing of image-processing methods for the quantitative assessment of airway hyperresponsiveness from high-resolution CT images. J Comput Assist Tomogr 1997; 21: 939-947.

6o. Mitchell AW, Wells AU, Hansell DM. Changes in cross-sectional area of the lungs on end expiratory computed tomography in normal individuals. Clinical Radiology 1996; 51: 804-806.

61. Montaudon M, Berger P, Cangini-Sacher A, et al. Bronchial measurement with three-dimensional quantitative thin-section $\mathrm{CT}$ in patients with cystic fibrosis. Radiology 2006; 242: 573-581.

62. Nakano Y, Muro S, Sakai H, et al. Computed tomographic measurements of airway dimensions and emphysema in smokers. Correlation with lung function. Am J Respir Crit Care Med 2000; 162: 1102-1108.

63. Nakano Y, Whittall KP, Kalloger SE, et al. Development and validation of human airway analysis algorithm using multidetector row CT. Proc SPIE 2002; 4683: 460-469.

64. Nakano Y, Wong JC, de Jong PA, et al. The prediction of small airway dimensions using computed tomography. Am J Respir Crit Care Med 2005; 171: 142-146.

65. Niimi A, Matsumoto $H$, Amitani R, et al. Airway wall thickness in asthma assessed by computed tomography. Relation to clinical indices. Am J Respir Crit Care Med 2000; 162: 1518-1523.

66. Okazawa M, Muller NL, McNamara AE, et al. Human airway narrowing measured using high resolution computed tomography. Am J Respir Crit Care Med 1996; 154: 1557-1562.

67. Patel BD, Coxson HO, Pillai SG, et al. Airway wall thickening and emphysema show independent familial aggregation in COPD. Am J Respir Crit Care Med 2008; 178: 500-505.

68. Reinhardt JM, D'Souza ND, Hoffman EA. Accurate measurement of intrathoracic airways. IEEE Trans Med Imaging 1997; 16: 820-827.

69. Saba OI, Hoffman EA, Reinhardt JM. Maximizing quantitative accuracy of lung airway lumen and wall measures obtained from $x$-ray CT imaging. J Appl Physiol 2003; 95: 1063-1075.

70. Hasegawa M, Nasuhara $Y$, Onodera $Y$, et al. Airflow limitation and airway dimensions in chronic obstructive pulmonary disease. Am J Respir Crit Care Med 2006; 173: 1309-1315.

71. Nakano Y, Muller NL, King GG, et al. Quantitative assessment of airway remodeling using high-resolution CT. Chest 2002; 122: 271S-275S.

72. Coxson HO. Quantitative computed tomography assessment of airway wall dimensions: Current status and potential applications for phenotyping chronic obstructive pulmonary disease. Proc Am Thorac Soc 2008; 5: 940-945.

73. Busacker A, Newell JD Jr, Keefe T, et al. A multivariate analysis of risk factors for the air-trapping asthmatic phenotype as measured by quantitative CT analysis. Chest 2009; 135: 48-56.

74. Nakano Y, Coxson HO, Bosan S, et al. Core to rind distribution of severe emphysema predicts outcome of lung volume reduction surgery. Am J Respir Crit Care Med 2001; 164: 2195-2199.

75. Orlandi I, Moroni C, Camiciottoli G, et al. Chronic obstructive pulmonary disease: Thin-section CT measurement of airway wall thickness and lung attenuation. Radiology 2005; 234: 604-610.

76. Aziz ZA, Wells AU, Desai SR, et al. Functional impairment in emphysema: Contribution of airway abnormalities and distribution of parenchymal disease. Am J Roentgenol 2005; 185: 1509-1515.

77. Washko GR, Hunninghake GM, Fernandez IE, et al. Lung volumes and emphysema in smokers with interstitial lung abnormalities. N Engl J Med 2011; 364: 897-906.

78. Gietema HA, Muller NL, Fauerbach PV, et al. Quantifying the extent of emphysema: Factors associated with radiologists' estimations and quantitative indices of emphysema severity using the eclipse cohort. Acad Radiol 2011; 18: 661-671.

79. Mayo JR, Aldrich J, Muller NL. Radiation exposure at chest CT: A statement of the fleischner society. Radiology 2003; 228: 15-21.

8o. Madani A, De Maertelaer V, Zanen J, et al. Pulmonary emphysema: Radiation dose and section thickness at multidetector CT quantification-comparison with macroscopic and microscopic morphometry. Radiology 2007; 243: 250-257.

\section{Suggested} answers

1. d.

2. d.

3. c.

4. a.

5. d. 